\title{
Cirurgia de varizes com preservação da veia safena magna: avaliação dos resultados tardios dos pacientes tratados com técnica de ligadura da junção safenofemoral
}

\author{
Varicose vein surgery with preservation of the great saphenous vein: \\ assessment of long-term results in patients treated by flush ligation \\ of the saphenofemoral junction.
}

\begin{abstract}
Resumo
Introdução: A veia safena magna (VSM) é o melhor substituto arterial nas revascularizacões das extremidades inferiores e tem sido utilizada nas pontes aortocoronárias, nos traumas vasculares dos membros, nas cirurgias para correção da insuficiência venosa crônica e nos acessos vasculares para hemodiálise. Assim, no tratamento cirúrgico das varizes primárias, a sua preservação é recomendável, sempre que possível. Quanto às técnicas cirúrgicas para preservação da VSM, os resultados publicados são controversos, havendo necessidade de melhor avaliação dos mesmos.
\end{abstract}

Hamilton Almeida Rollo*

Objetivo: Avaliar os resultados tardios de técnica cirúrgica para preservação da VSM nos pacientes com varizes primárias dos membros inferiores e com insuficiência da VSM por refluxo na junção safeno-femoral (JSF).
Métodos: Foi realizado um estudo longitudinal de uma série de casos atendidos consecutivamente no Serviço de Cirurgia Vascular do Hospital das Clínicas da Faculdade de Medicina de Botucatu, Universidade Estadual de São Paulo (UNESP), Botucatu, SP. Todos os pacientes eram portadores de varizes primárias dos membros inferiores, com insuficiência da VSM por refluxo na JSF, e foram submetidos ao tratamento cirúrgico com técnica para preservação da VSM (ligadura rasante da JSF, com preservação das tributárias da crossa e da VSM e retirada das veias varicosas através de incisões escalonadas com agulha de crochê). Foram feitas avaliações pré e pós-operatórias pela clínica, mapeamento dúplex (MD) e fotopletismografia (FPG). Os diâmetros da VSM foram avaliados pelo MD em cinco níveis, sendo dois na coxa, dois na perna e um no joe1ho. Um subgrupo de 39 pacientes foi avaliado tardiamente ( $\geq 5$ anos).

\footnotetext{
* Livre-docente. Professor adjunto, Disciplina de Cirurgia Vascular, Departamento de Cirurgia e Ortopedia, Faculdade de Medicina de Botucatu, Universidade Estadual Paulista (UNESP), Botucatu, SP. Chefe, Disciplina de Cirurgia Vascular, Faculdade de Medicina de Botucatu, UNESP, Botucatu, SP. Chefe, Laboratório Vascular, Hospital das Clínicas, Faculdade de Medicina de Botucatu, UNESP, Botucatu, SP.

Tese de livre-docência desenvolvida na Disciplina de Cirurgia Vascular e apresentada ao Departamento de Cirurgia e Ortopedia, Faculdade de Medicina de Botucatu (FMB), Universidade Estadual de São Paulo (UNESP), Botucatu, SP, em 19/03/08.
}

Banca: Prof. Dr. Francisco Humberto de Abreu Maffei, Profa. Dra. Maria Aparecida Coelho de Arruda Henry, Prof. Dr. Emil Burihan, Prof. Dr. Carlos Eli Piccinato, Profa. Dra. Ana Terezinha Guillaumon.

Não foram declarados conflitos de interesse associados à publicação deste resumo.

Artigo submetido em 10.04.08, aceito em 04.08.08.

J Vasc Bras. 2008;7(3):289-290.

Copyright@ 2008 by Sociedade Brasileira de Angiologia e de Cirurgia Vascular 
Resultados: Foram estudados 77 membros inferiores de 67 pacientes, sendo 34 membros com menos de 5 anos e 43 com 5 anos ou mais de seguimento. Houve redução significativa $(\mathrm{p}<0,05)$ dos diâmetros da VSM no pósoperatório em $82,3 \%$ dos membros, e esta redução se manteve ao longo do tempo. A ocorrência de tromboflebite foi detectada em apenas 9\% das VSM, sendo que nos outros $91 \%$ dos membros as VSM estavam totalmente pérvias. Houve recorrência de refluxo na JSF em $5,9 \%$ dos membros no grupo avaliado com $<5$ anos e em $18,6 \%$ nos com $\geq 5$ anos, diferença esta não significativa $(p>0,05)$. A maioria das VSM preservadas tinha fluxo bidirecional de baixa velocidade. Houve predominância da avaliação clínica boa ou ótima (79,4\%), e esta se manteve a longo prazo. A recidiva de varizes foi de
$35,3 \%$ (mais freqüente na perna) e se agravou ao longo do tempo $(69,8 \%)$, atingindo significância $(\mathrm{p}<0,05)$. A FPG foi realizada em 69 membros no pós-operatório, e em $85,7 \%$ deles o resultado foi normal, não havendo diferença significante entre os grupos precoce e tardio. Nos pacientes com recidiva, a FPG estava alterada em 73,3\% $(\mathrm{p}<0,05)$.

Conclusão: Com a técnica cirúrgica utilizada para preservação da VSM, foi possível preservá-la em condições adequadas para constituir substituto arterial ao longo do tempo na maioria dos membros inferiores.

Palavras-chave: Varizes, veia safena magna, ultrasom, pletismografia, cirurgia. 